\title{
TWELVE WEEKS CLA SUPPLEMENTATION DECREASES THE HIP CIRCUMFERENCE IN OVERWEIGHT AND OBESE WOMEN A DOUBLE-BLIND, RANDOMIZED, PLACEBO-CONTROLLED TRIAL
}

\author{
Edyta Mądry¹, Izabela Chudzicka-Strugała², Katarzyna Grabańska-Martyńska², \\ Klaudia Malikowska ${ }^{4}$, Philip Grebowiec ${ }^{4}$, Aleksandra Lisowska ${ }^{4}$, Paweł Bogdański ${ }^{5}$, \\ Jarosław Walkowiak ${ }^{4 冈}$
}

${ }^{1}$ Department of Physiology, Poznan University of Medical Sciences

Szpitalna 27/33, 60-572 Poznań, Poland

${ }^{2}$ Department of Medical Microbiology, Poznan University of Medical Sciences

Szpitalna 27/33, 60-572 Poznań, Poland

${ }^{3}$ Department of Internal Medicine, Metabolic Disorders and Hypertension, Poznan University of Medical Sciences

Szpitalna 27/33, 60-572 Poznań, Poland

${ }^{4}$ Department of Pediatric Gastroenterology and Metabolic Diseases, Poznan University of Medical Sciences

Szpitalna 27/33, 60-572 Poznań, Poland

${ }^{5}$ Department of Education and Obesity Treatment and Metabolic Disorders, Poznań University of Medical Sciences

Szpitalna 27/33, 60-572 Poznań, Poland

\begin{abstract}
Background. Conjugated linoleic acid (CLA) reduces body weight (BW), body fat mass (BFM), and increases or maintains lean body mass in animals. However, the results concerning the effect of CLA on weight reduction in humans are contradictory. The present study aimed to evaluate the effect of CLA supplementation on the BW and anthropometric parameters (waist and hip circumferences) in overweight and obese adult women.

Material and methods. A total of 74 subjects (BMI: $28-42 \mathrm{~kg} / \mathrm{m}^{2}$ ) were included in a double blind, placebocontrolled trial. Subjects were randomized into two groups, those supplemented with either $3.0 \mathrm{~g} / \mathrm{d}$ CLA or with placebo (sunflower oil) for 12 weeks.

Results. CLA significantly decreased the hip circumferences compared to placebo $(p=0.016209)$, but had no effect on body weight, BMI, or waist circumference. The number of subjects with a reduction in hip circumference in the CLA group was significantly larger compared to that in the placebo group $(p=0.0017$; NNT $=2.65$; CI [6.27-1.685]).

Conclusions. In conclusion, our findings do not support the hypothesis that 12 weeks CLA supplementation, as dosed in the present study, is effective for body weight reduction in overweight and obese women. However, its local action in decreasing the hip circumference seems to be encouraging and suggests that CLA may represent an attractive dietary supplement.
\end{abstract}

Key words: CLA, placebo, hip circumference, waist circumference, body weight, BMI 


\section{INTRODUCTION}

Nowadays, it is well understood that stopping or slowing down the epidemic of obesity, on a worldwide scale, is not only a challenge but an obligation of the scientific world. This stimulates the intensive search for factors, tools, and methods which could affect the energy equilibrium. Particularly important and pragmatic is the identification of substances found in foods naturally that influence the energy balance. This issue is part of a very current topic concerning so-called functional foods, in the context of which the tenet "Let food be thy medicine and medicine be thy food" (espoused by Hippocrates nearly 2,500 years ago) is receiving renewed interest.

Although the vast number of naturally occurring health enhancing substances are of plant origin, there are a number of physiologically active components in animal products that deserve attention for their potential role in optimizing health (Hasler, 1989). Intensively investigated for almost 30 years, one of these substances of animal origin is conjugated linoleic acid (CLA) - a group of positional and geometric isomers of octadecadienoic acid (18:2) (Czochralska-Duszyńska et al., 2015). CLA was first isolated by Ha et al., from grilled beef in 1987 (Ha et al., 1987). Over the past decade, is has been shown to be effective in suppressing forestomach tumors in mice, aberrant colonic crypt foci in rats, and mammary carcinogenesis in rats (Ip and Scimeca, 1997). More recently, CLA has been investigated for its ability to change body composition, suggesting a role as a weight reduction agent. Mice fed CLA-supplemented diets (0.5\%) exhibited $60 \%$ lower body fat and $14 \%$ increased lean body mass relative to controls (Park et al., 1997). However, in humans, despite the numerous of studies, results concerning the effect of CLA on weight reduction are contradictory.

Thus, the present study aimed to assess the impact of 12 weeks of CLA supplementation on the BMI and anthropometric parameters in overweight and obese women. The hypothesis was that CLA supplementation would reduce BMI, waist and hip circumferences.

\section{MATERIAL AND METHODS}

\section{Methods}

The study was conducted according the standards of a randomized, double blind, placebo-controlled trial and was carried out independently of any commercial entities. Subjects were recruited from the Obesity and Overweight Treatment Clinic of Poznan University of Medical Sciences, Poznań, Poland between July 2014 and May 2015. Women over 18 years with a BMI $\geq 25$ $\mathrm{kg} / \mathrm{m}^{2}$ were eligible to participate in the study. Exclusion criteria included the following: a history of chronic systemic disease (with the exception of hypertention), Celiac disease, Type 2 Diabetes, liver and/or pancreatic disease, current or recent (within the preceding month) treatment with CLA and agents interfering with fat digestion and/or absorption (chitosan, orlistat, green tea), and pregnancy (Łochocka et al., 2014). All studyparticipants signed the informed consent before entering the study. Women eligible for study participation were randomly assigned to receive CLA or a comparable placebo. Both products, CLA and placebo, were produced and supplied by Olimp Laboratories (Dębica, Poland). Both supplements were packed in identical transparent capsules with a yellowish tint, and held in similar blisters packets. The CLA capsules contained $0.5 \mathrm{~g}$ of $80 \%$ CLA (50:50 cis-9, trans-11 and trans-10, cis-12 isomers), while the placebo capsules contained $0.5 \mathrm{~g}$ of sunflower oil, resembling the average fatty acid composition of the fat consumed by the Polish population. The composition of fatty acids of both products has been presented in Table 1 .

All women enrolled to the study were instructed to take 2 capsules of the provided product three times a day with a meal for 12 weeks. A criterion for completion of the study included the consumption of $75 \%$ of the supplement provided. The study participants were also instructed to maintain an isocaloric diet, not changing their eating habits during the research period, as well as for maintaining the current lifestyle with a special emphasis on the maintaining the current volume of the physical activity.

Upon entry to the study, each woman underwent a physical examination including the evaluation of anthropometric measurements: weight, height, BMI, waist and hip circumference. After completion of the study, the same parameters were assessed again. 
Table 1. Fatty acid composition of CLA and placebo (sunflower oil)

\begin{tabular}{lcc}
\hline Fatty acid & $\begin{array}{c}\text { CLA } \\
\%\end{array}$ & $\begin{array}{c}\text { Placebo } \\
\%\end{array}$ \\
\hline C16:0 & 3.6 & 4.8 \\
C18:0 & 1.1 & 2.1 \\
C18:1 & 12.9 & 10.2 \\
C18:2 & 1.2 & 61.2 \\
non-conjugated & & \\
C18:3 & 0.8 & 21.7 \\
C20:0 & 0.4 & - \\
$c 9, t 11$ CLA & 40.0 & - \\
$t 10, c 12$ CLA & 40.0 & - \\
\hline
\end{tabular}

The process of randomization was performed using a computer-generated number system. The randomization list was supervised by a person with no clinical involvement in the study. The participants and investigators were blinded to the assigned treatment throughout the entire period of the study. The codes of randomization were secured until all data were analysed.

Statistical analyses were performed using the data analysis software system STATISTICA (version 10; StatSoft, Poland). Mann-Whitney U test was used for comparison between the groups (CLA vs. placebo). Within-group analyses (baseline vs. 12 weeks) were performed using the Wilcoxon test. Differences were considered significant when the $p$ value was $<0.05$.

The primary endpoint settled for the major aim of the study was the difference in starch and lipid digestion between the groups as assessed by a starch breath test and a mixed triglyceride breath test, respectively. Considering the data from our previous studies, it was assumed that the mean difference would account for $75 \%$ of those observed by us earlier. To detect this difference with a power of $80 \%$ and a significance level of $5 \%$ while taking into account a potential drop-out rate of $20 \%$, it was calculated that thirty-seven patients would be needed to be studied in each group (Łochocka et al., 2015; Walkowiak et al., 2013).

The project has been awarded a research grant (number 504-06-01103115-000-15-07588) from Nutricia Foundation, and its duration was planned for 3 years. The Nutricia Foundation had no role in the design and analysis of the study results or in the writing of this article. The protocol of the trial was approved by the Bioethical Committee of Poznan University of Medical Sciences, Poland and all of the procedures were conducted according to the guidelines laid down in the Declaration of Helsinki.

\section{RESULTS}

A scheme depicting the progression of participants through the study has been shown in Figure 1. Of the 187 registered subjects, 81 met the inclusion criteria and were invited to participate in the study. Seven of them were excluded due to the failures of screening (personal problems -1 ; ovarian tumor suspected -1 ; shortage of time - 3; stomach pain, diarrhea - 1; difficulty cooperating -1 ). Finally, 74 women underwent randomization. Among them, thirty-seven were assigned to the experimental CLA group and thirty-seven were included to the placebo group. At 12 weeks (the end of the intervention), data from sixty-two $(83.8 \%)$ subjects were available for analysis. Dropouts comprised of women who did not arrive for the final study visit (3 subjects from the CLA group; 4 subjects from the placebo group), reported adverse effects associated with the use of tested product (nausea -2 subject from the placebo group; 1 subject from the CLA group, rash - 1 subject from the placebo group), and 1 woman from the CLA group who became pregnant. The dropout rates were comparable in both arms of the study $-13.5 \%$ in the CLA and $18.9 \%$ in the placebo group, respectively. The baseline clinical characteristics did not differ between the studied groups; they have been presented in Table 2.

The comparisons between the studied groups for all of the outcome measures, including the absolute values and the differences in absolute values, have been summarized in Table 3. There were no significant differences between the groups with regard to body weight, BMI, and waist circumference. The statistically significant difference was limited to the hip circumferences $(p=0.016209)$. Within-group analyses for the CLA group (baseline vs. 12 week results) have shown statistically significant differences in waist circumference $(p=0.003730)$ and hip circumference $(p=0.000805)$, no differences in the placebo group 


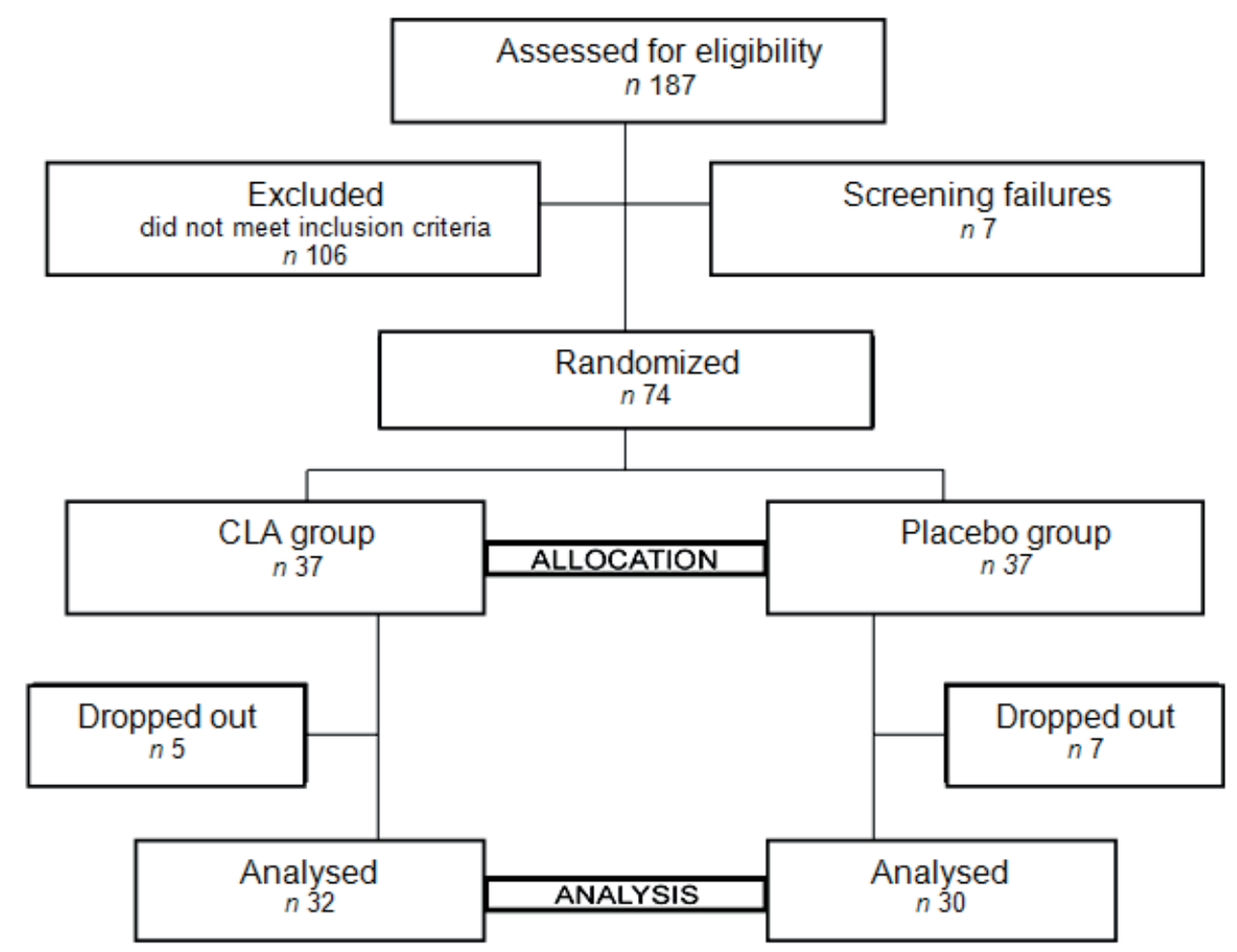

Fig. 1. Flowchart illustrating the progression of participants through the study

Table 2. Baseline characteristics of the study groups

\begin{tabular}{|c|c|c|c|c|c|}
\hline & \multicolumn{2}{|c|}{$\begin{array}{l}\text { CLA group } \\
(n=37)\end{array}$} & \multicolumn{2}{|c|}{$\begin{array}{l}\text { Placebo group } \\
\quad(n=37)\end{array}$} & \multirow{2}{*}{$p$} \\
\hline & Median & $1^{\text {st }}-3^{\text {rd }}$ quartile & Median & $1^{\text {st }}-3^{\text {rd }}$ quartile & \\
\hline $\begin{array}{l}\text { Age } \\
\text { years }\end{array}$ & 54 & $43-59$ & 54 & $45-61$ & 0.991427 \\
\hline $\begin{array}{l}\text { Body weight } \\
\mathrm{kg}\end{array}$ & 90.0 & $80.1-99.6$ & 91.6 & $85.4-101.0$ & 0.354627 \\
\hline $\begin{array}{l}\text { Body height } \\
\mathrm{cm}\end{array}$ & 163 & $160-166$ & 163 & $159-167$ & 0.706790 \\
\hline $\begin{array}{l}\mathrm{BMI} \\
\mathrm{kg} / \mathrm{m}^{2}\end{array}$ & 34.00 & $30.70-37.58$ & 35.36 & $31.75-38.62$ & 0.504919 \\
\hline $\begin{array}{l}\text { Hip circumference } \\
\mathrm{cm}\end{array}$ & 116.0 & $110.0-127.0$ & 119.0 & $111.5-125.5$ & 0.598344 \\
\hline $\begin{array}{l}\text { Waist circumference } \\
\mathrm{cm}\end{array}$ & 108.0 & $104.0-114.0$ & 109.0 & $103.0-115.0$ & 0.829835 \\
\hline
\end{tabular}

$p$ - statistical significance. 
Mądry, E., Chudzicka-Strugała, I., Grabańska-Martyńska, K., Malikowska, K., Grebowiec, P., Lisowska, A., Bogdański, P., Walkowiak, J. (2016). Twelve weeks CLA supplementation decreases the hip circumference in overweight and obese women. A double-blind, randomized, placebo-controlled trial. Acta Sci. Pol. Technol. Aliment., 15(1), 107-113. DOI: 10.17306/J.AFS.2016.1.11

Table 3. Effects of CLA and placebo on outcome measures

\begin{tabular}{|c|c|c|c|c|c|}
\hline & & & & $\begin{array}{l}\text { group } \\
30)\end{array}$ & $p$ \\
\hline & Median & $1^{\text {st }}-3^{\text {rd }}$ quartile & Median & $1^{\text {st }}-3^{\text {rd }}$ quartile & \\
\hline $\begin{array}{l}\text { Body weight } \\
\mathrm{kg}\end{array}$ & 92.7 & $(79.5)-(99.3)$ & 96.1 & $(83.2)-(104.8)$ & 0.258850 \\
\hline $\begin{array}{l}\text { Body weight } \\
\text { difference } \\
\mathrm{kg}\end{array}$ & -0.4 & $(-1.5)-(0.6)$ & 0.2 & $(-1.1)-(1.2)$ & 0.214185 \\
\hline $\begin{array}{l}\mathrm{BMI} \\
\mathrm{kg} / \mathrm{m}^{2}\end{array}$ & 34.72 & $(30.83)-(37.76)$ & 36.34 & $(31.0)-(39.31)$ & 0.302826 \\
\hline $\begin{array}{l}\text { BMI difference } \\
\mathrm{kg} / \mathrm{m}^{2}\end{array}$ & -0.21 & $(-0.71)-(0.19)$ & 0.04 & $(-0.48)-(0.41)$ & 0.316240 \\
\hline $\begin{array}{l}\text { Waist circumference } \\
\mathrm{cm}\end{array}$ & 104.8 & $(100.8)-(113.0)$ & 110.0 & $(101.1)-(114.1)$ & 0.381273 \\
\hline $\begin{array}{l}\text { Waist circumference } \\
\text { difference } \\
\mathrm{cm}\end{array}$ & -2.3 & $(-4.6)-(-0.4)$ & -1.3 & $(-2.8)-(0.9)$ & 0.175290 \\
\hline $\begin{array}{l}\text { Hip circumference } \\
\mathrm{cm}\end{array}$ & 115.0 & $(109.8)-(123.5)$ & 120.3 & $(110.0)-(127.8)$ & 0.330033 \\
\hline $\begin{array}{l}\text { Hip circumference } \\
\text { difference } \\
\mathrm{cm}\end{array}$ & -2.0 & $(-5.0)-(-0.5)$ & 0.0 & $(-3.1)-(1.5)$ & 0.016209 \\
\hline
\end{tabular}

$p$ - statistical significance.

were stated. In 32 subjects receiving CLA as compared with 30 women receiving placebo there were no differences in the decrease of body weight $-18(56.2 \%) v s$. $11(36.7 \%)$ subjects, BMI - $19(59.4 \%)$ vs. $12(40.0 \%)$ subjects and waist circumference $-24(75.0 \%)$ vs. 20 (66.7\%) subjects (Table 4). However, a decrease in hip circumference was found in twenty seven (84.4\%) women receiving CLA which significantly differed from the placebo group where a decrease in hip circumference was observed in only $14(46.7 \%)$ subjects $(p=0.0017$; NNT $=2.65$; CI [6.27-1.685]).

\section{DISCUSSION}

The results of the present study showed that 12 weeks of supplementation with CLA at a dose of $3 \mathrm{~g}$ per day decreases the hip circumference in obese women even though it is not effective for body weight reduction.
There are 2 major strengths of the present study. The first is its design: we conducted a randomized, double-blind, placebo-controlled trial with the appropriate methods used to generate allocation sequence and allocation concealment, which is considered the strongest research design for evaluating the effects of interventional studies (Altman and Dore, 1990, Juni et al., 2001). The second strength is the presentation of the study results and construction of the manuscript in accordance with the standards of the CONSORT (Consolidated Statement of Reporting Trials) updated in 2010 (Moher et al., 2010). Our findings do not support the hypothesis that 12 weeks CLA supplementation, as dosed in the present study, is effective for body weight reduction in overweight and obese women. However, the present investigation has some limitations. Although $83.8 \%$ of the 74 enrolled subjects had completed the study, the main limitation may be related to the low number of patients included. 
Mądry, E., Chudzicka-Strugała, I., GrabańskaMartyńska, K., Malikowska, K., Grebowiec, P., Lisowska, A., Bogdański, P., Walkowiak, J. (2016). Twelve weeks CLA supplementation decreases the hip circumference in overweight and obese women. A double-blind, randomized, placebo-controlled trial. Acta Sci. Pol. Technol. Aliment., 15(1), 107-113. DOI: 10.17306/J.AFS.2016.1.11

Table 4. The decrease of anthropometric parameters in CLA and placebo group

\begin{tabular}{|c|c|c|c|c|}
\hline & \multicolumn{2}{|c|}{ Decrease of values $n, \%$} & \multirow{2}{*}{$\begin{array}{c}\mathrm{RR} \\
(95 \% \mathrm{CI})\end{array}$} & \multirow{2}{*}{$p$} \\
\hline & CLA group & placebo group & & \\
\hline Body weight & $18(56.3)$ & $11(36.7)$ & $\begin{array}{c}1.5341 \\
(0.8755-2.688)\end{array}$ & 0.1348 \\
\hline BMI & $19(59.4)$ & $12(40.0)$ & $\begin{array}{c}1.4844 \\
(0.8793-2.5059)\end{array}$ & 0.1393 \\
\hline Waist circumference & $24(75.0)$ & $20(66.7)$ & $\begin{array}{c}1.1250 \\
(0.8148-1.5532)\end{array}$ & 0.4742 \\
\hline Hip circumference & $27(84.4)$ & $14(46.7)$ & $\begin{array}{c}1.8080 \\
(1.1992-2.726)\end{array}$ & 0.0047 \\
\hline
\end{tabular}

$\mathrm{RR}$ - relative risk, $\mathrm{CI}$ - confidence interval, $p$ - statistical significance.

Assumptions which guided us in the calculation of the study group size were used for the other purposes as described in methods.

As in our study, no significant effect of CLA supplementation on body weight was noted in several other randomized, placebo controlled trials which comprised an smaller groups of subjects (Blankson et al., 2000; Carvalho et al., 2012; Joseph et al., 2011; Smedman and Vessby, 2000; Thom et al., 2001; Zambell et al., 2000).

Henrietta Blankson et al. (2000) have shown that in a group of 60 overweight and obese adults receiving different doses of CLA $(1.7 \mathrm{~g}, 3.4 \mathrm{~g}, 5.1 \mathrm{~g}$ or $6.8 \mathrm{~g})$ for 12 weeks, there was a significantly higher reduction in body fat mass compared with the placebo group $(p=0.03)$. The reduction of BFM within the groups was significant for the groups receiving 3.4 and $6.8 \mathrm{~g}$ of CLA ( $p=0.05$ and $p=0.02$, respectively). As in our study, none of the groups had shown a significant reduction in weight or BMI after 12 weeks of intervention.

In a study by Carvalho et al. (2012), 14 women diagnosed with metabolic syndrome received either light strawberry jam enriched with microencapsulated CLA ( $3 \mathrm{~g} /$ day) or jam that was unenriched as a control. The intervention was associated with a hypocaloric diet for 90 days. Supplementation did not alter the waist circumference, but there was a reduction in BFM detected in the CLA group after 30 days ( $p=$ 0.02 ), which was maintained until the 90th day of the intervention $(p=0.02)$. The placebo group showed this effect only after 90 days $(p=0.02)$. However, the decrease in waist circumference in this group of subjects $(p=0.03)$ was also observed. An important limitation of this randomized trial was undoubtedly a very small sample size - both groups comprised of 7 women. Moreover, the observed effects may be primarily attributable to the decrease of energy intake.

Gaullier et al. (2007) studying a group of 105 subjects (BMI: $28-32 \mathrm{~kg} / \mathrm{m}^{2}$ ) supplemented with either $3 \times 4 \mathrm{~g} / \mathrm{d}$ CLA or placebo, found no difference between the groups in body weight and BMI after 6 months of supplementation which remains in accordance with the results of the present study. However, the loss of weight and decrease in BMI after CLA supplementation was documented for the subgroup of individuals with a BMI $\geq 30 \mathrm{~kg} / \mathrm{m}^{2}(p=0.031)$. Moreover, CLA significantly decreased body fat mass at month 3 and at month 6 compared with placebo in the cited study. Interestingly, the reduction of fat mass concerned only women with BMI $>30 \mathrm{~kg} / \mathrm{m}^{2}$ and was located mostly in the legs. The phenomenon of local decrease in fat, particularly in the legs, can partially explain the observed result of the exclusive reduction of hip circumference in our study.

\section{CONCLUSIONS}

Our findings do not support the hypothesis that 12 weeks CLA supplementation, as dosed in the present study, is effective for body weight reduction in overweight and obese women. However, its local action in 
decreasing the hip circumference seems to be encouraging and suggests that CLA may represent an attractive dietary supplement. Larger randomized, placebo controlled, long-term studies to unravel the potential benefits of CLA supplementation in overweight and obese subjects are needed.

\section{ACKNOWLEDGMENTS}

Olimp labs kindly provided CLA and placebo capsules for the study.

\section{REFERENCES}

Altman, D. G., Dore, C. J. (1990). Randomisation and baseline comparisons in clinical trials. Lancet, 20, 335, 149-153.

Blankson, H., Stakkestad, J. A., Fagertun, H., Thom, E., Wadstein J., Gudmundsen O. (2000). Conjugated linoleic acid reduces body fat mass in overweight and obese humans. J. Nutr., 130, 12, 2943-2948.

Carvalho, R. F., Uehara, S. K., Rosa, G. (2012). Microencapsulated conjugated linoleic acid associated with hypocaloric diet reduces body fat in sedentary women with metabolic syndrome. Vasc. Health. Risk. Manag., 8, 661-667.

Czochralska-Duszyńska, A., Grabańska, K., Mądry, E., Bogdański, P. (2015). Sprzężone kwasy linolowe w terapii wybranych jednostek chorobowych - fakty i kontrowersje [Conjugated linoleic acids in the therapy of selected diseases - facts and controversies]. Forum Zab. Metabol., 1, 25-30 [in Polish].

Gaullier, J. M., Halse, J., Høivik, H. O., Høye, K., Syvertsen, C., Nurminiemi, ..., Gudmundsen O. (2007). Six months supplementation with conjugated linoleic acid induces regional-specific fat mass decreases in overweight and obese. Br. J. Nutr., 97, 3, 550-560.

Ha, Y. L., Grimm, N. K., Pariza, M. W. (1987). Anticarcinogens from fried ground beef: heat-altered derivatives of linoleic acid. Carcinogenesis, 8, 12, 1881-1887.

Hasler, C. M. (1998). A new look at an ancient concept. Chem. Industry, 2, 84-89.

Ip, C., Scimeca, J. A. (1997). Conjugated linoleic acid and linoleic acid are distinctive modulators of mammary carcinogenesis. Nutr. Cancer, 27, 131-135.
Joseph, S. V., Jacques, H., Plourde, M., Mitchell, P. L., McLeod, R. S., Jones, P. J. (2011). Conjugated linoleic acid supplementation for 8 weeks does not affect body composition, lipid profile, or safety biomarkers in overweight, hyperlipidemic men. J. Nutr. 141, 7, 1286-1291.

Juni, P., Altman, D. G., Egger, M. (2001). Systematic reviews in health care: Assessing the quality of controlled clinical trials. BMJ, 7, 323, 42-46.

Łochocka, K., Bajerska, J., Glapa, A., Fidler-Witoń, E., Nowak, J. K., Szczapa, T., ..., Walkowiak, J. (2015). Green tea extract decreases starch digestion and absorption from a test meal in humans: a randomized, placebocontrolled crossover study. Sci. Rep., 5, 12015, 1-5.

Łochocka, K., Glapa, A., Nowak, J. K., Duś-Żuchowska, M., Grabańska, K., Bogdański, P., ..., Walkowiak, J. (2014). Clinical outcomes of conjugated linoleic acid supplementation in the overweight and the obese: a study protocol. J. Med. Sci., 83, 4, 338-341.

Moher, D., Hopewell, S., Schulz, K. F., Montori, V., Gøtzsche, P. C., Devereaux, P. J., ..., Altman, D. G. (2010). CONSORT 2010 explanation and elaboration: updated guidelines for reporting parallel group randomised trials. J. Clin. Epidemiol., 63, 8, 1-37.

Park, Y., Albrigh, K. J., Il, W., Storkson, J. M., Cook, M. E., Pariza, M. W. (1997). Effect of conjugated linoleic acid on body composition in mice. Lipids, 32, 853-858.

Smedman, A., Vessby, B. (2001). Conjugated linoleic acid supplementation in humans--metabolic effects. Lipids, 36, 8, 773-781.

Thom, E., Wadstein, J., Gudmundsen, O. (2001). Conjugated linoleic acid reduces body fat in healthy exercising humans. Int. Med. Res., 29, 5, 392-396.

Walkowiak, J., Bajerska, J., Kargulewicz, A., Lisowska, A., Siedlerski, G., Szczapa, T., ..., Grzymisławski, M. (2013). Single dose of green tea extract decreases lipid digestion and absorption from a test meal in humans. Acta. Bioch. Pol., 60, 3, 481-483

Zambell, K. L., Keim, N. L., Van Loan, M. D., Gale, B., Benito, P., Kelley, D. S., Nelson, G. J. (2000). Conjugated linoleic acid supplementation in humans: effects on body composition and energy expenditure. Lipids, 35, 7, 777-782. 